\title{
An oscillation criterion of linear delay differential equations
}

\author{
George E. Chatzarakis ${ }^{1 *}$, Božena Dorociaková ${ }^{2}$ and Rudolf Olach²
}

"Correspondence:
geaxatz@otenet.gr;
gea.xatz@aspete.gr
${ }^{1}$ Department of Electrical and
Electronic Engineering Educators,
School of Pedagogical and
Technological Education (ASPETE),
Athens, Greece
Full list of author information is
available at the end of the article

available at the end of the article

\begin{abstract}
In this paper, we present a new sufficient condition for the oscillation of all solutions of linear delay differential equations. The obtained result improves known conditions in the literature. We also give an example to illustrate the applicability and strength of the obtained condition over known ones.
\end{abstract}

MSC: Primary 34K06; secondary 34K11

Keywords: Oscillation; Delay differential equation; Oscillatory solutions; Nonoscillatory solutions; Sufficient conditions

\section{Introduction}

This paper is devoted to studying the oscillation of the first-order delay differential equation of the form

$$
x^{\prime}(t)+p(t) x(t-r(t))=0, \quad t \geq T_{0},
$$

where $T_{0} \in \mathbb{R}_{+}, p, r \in C\left(\left[T_{0}, \infty\right),(0, \infty)\right)$, and $0<r(t)<t$, and $\lim _{t \rightarrow \infty}(t-r(t))=\infty$.

The problem of the oscillatory properties of the solutions of delay differential equations has been recently investigated by many authors. See, for example [1-11] and the references therein. We mention some results for the purpose of this paper.

Chatzarakis and $\mathrm{Li}$ [5] studied the oscillation of delay differential equations with nonmonotone arguments. The results reported in this paper (regarding the oscillation of firstorder delay differential equations) have numerous applications (e.g., comparison principles) in the study of oscillation and asymptotic behavior of higher-order differential equations; see, for instance, $[1,6,10,11]$ for more detail.

In 1972, Ladas, Lakshmikantham, and Papadakis [9] proved that if

$$
\limsup _{t \rightarrow \infty} \int_{t-r(t)}^{t} p(s) d s>1
$$

then all solutions of (1) are oscillatory.

(c) The Author(s) 2021. This article is licensed under a Creative Commons Attribution 4.0 International License, which permits use sharing, adaptation, distribution and reproduction in any medium or format, as long as you give appropriate credit to the original author(s) and the source, provide a link to the Creative Commons licence, and indicate if changes were made. The images or other third party material in this article are included in the article's Creative Commons licence, unless indicated otherwise in a credit line to the material. If material is not included in the article's Creative Commons licence and your intended use is not permitted by statutory regulation or exceeds the permitted use, you will need to obtain permission directly from the copyright holder. To view a copy of this licence, visit http://creativecommons.org/licenses/by/4.0/. 
Ladas [8] in 1979, and Koplatadze and Chanturiya [7] in 1982 improved (2) to

$$
\liminf _{t \rightarrow \infty} \int_{t-r(t)}^{t} p(s) d s>\frac{1}{e}
$$

Concerning the constant $\frac{1}{e}$ in (3), it is to be pointed out that if the inequality

$$
\int_{t-r(t)}^{t} p(s) d s \leq \frac{1}{e}
$$

eventually holds, then, according to a result in [4], (1) has a nonoscillatory solution.

In the recent paper [3] the authors established the following oscillation criterion for (1) when $r(t)=\tau, \tau>0$.

Theorem $1.1([3])$ Let $p:\left[T_{0}, \infty\right) \rightarrow \mathbb{R}_{+}$be a nonnegative, bounded, and uniformly continuous function such that

$$
\liminf _{t \rightarrow \infty} \int_{t-\tau}^{t} p(s) d s>0 .
$$

Moreover, suppose that the function

$$
A(t)=\int_{t-\tau}^{t} p(s) d s, \quad t \geq T_{0}+\tau,
$$

is slowly varying at infinity. Then

$$
\limsup _{t \rightarrow \infty} \int_{t-\tau}^{t} p(s) d s>\frac{1}{e}
$$

implies that all solutions of (1) are oscillatory.

Our aim is establishing a new condition for the oscillation of all solutions of (1), including the cases where conditions (2)-(3) and Theorem 1.1 cannot be applied. We also give an example illustrating the applicability and strength of the obtained condition over the known ones.

\section{Main result}

The proof of our main result is essentially based on the following lemmas.

Lemma 2.1 Let $x$ be an eventually positive solution of (1). Then for sufficiently large $t_{0}>$ $T_{0}$,

$$
\ln \frac{x(t-\tau)}{x(t)}=\int_{t-\tau}^{t} p(s) \frac{x(s-r(s))}{x(s)} d s, \quad t \geq t_{0}+\tau
$$

Proof Let $x$ be an eventually positive solution of (1). Then $x(t-r(t))>0$ for $t \geq t_{0}+\tau$, where $t_{0}>T_{0}$ is sufficiently large. From (1), for $t \geq t_{0}+\tau$, we obtain

$$
\frac{x^{\prime}(t)}{x(t)}+p(t) \frac{x(t-r(t))}{x(t)}=0
$$


or

$$
\int_{t-\tau}^{t} \frac{x^{\prime}(s)}{x(s)} d s+\int_{t-\tau}^{t} p(s) \frac{x(s-r(s))}{x(s)} d s=0
$$

that is,

$$
\ln \frac{x(t-\tau)}{x(t)}=\int_{t-\tau}^{t} p(s) \frac{x(s-r(s))}{x(s)} d s, \quad t \geq t_{0}+\tau .
$$

The proof of the lemma is complete.

Lemma 2.2 Let $x$ be an eventually positive solution of (1). Then

$$
\begin{aligned}
\ln \frac{x(t-\tau)}{x(t)}= & p(t) \int_{t-\tau}^{t} \frac{x(s-r(s))}{x(s)} d s \\
& +[p(t)-p(t-\tau)] \int_{t_{0}}^{t-\tau} \frac{x(s-r(s))}{x(s)} d s \\
& -\int_{t-\tau}^{t} p^{\prime}(s) \int_{t_{0}}^{s} \frac{x(u-r(u))}{x(u)} d u d s, \quad t \geq t_{0}+\tau .
\end{aligned}
$$

Proof It is obvious that

$$
\begin{array}{rl}
\int_{t-\tau}^{t} & p(s) \frac{x(s-r(s))}{x(s)} d s \\
= & p(t) \int_{t-\tau}^{t} \frac{x(s-r(s))}{x(s)} d s \\
& \quad+[p(t)-p(t-\tau)] \int_{t_{0}}^{t-\tau} \frac{x(s-r(s))}{x(s)} d s-\int_{t-\tau}^{t} p^{\prime}(s) \int_{t_{0}}^{s} \frac{x(u-r(u))}{x(u)} d u d s,
\end{array}
$$

or

$$
\begin{aligned}
\ln \frac{x(t-\tau)}{x(t)}= & p(t) \int_{t-\tau}^{t} \frac{x(s-r(s))}{x(s)} d s \\
& +[p(t)-p(t-\tau)] \int_{t_{0}}^{t-\tau} \frac{x(s-r(s))}{x(s)} d s \\
& -\int_{t-\tau}^{t} p^{\prime}(s) \int_{t_{0}}^{s} \frac{x(u-r(u))}{x(u)} d u d s, \quad t \geq t_{0}+\tau .
\end{aligned}
$$

The proof of the lemma is complete.

Now we focus on the function

$$
R(t)=-\int_{t-\tau}^{t} p^{\prime}(s) \int_{t_{0}}^{s} \frac{x(u-r(u))}{x(u)} d u d s, \quad t \geq t_{0}+\tau .
$$

Lemma 2.3 Let $x$ be an eventually positive solution of (1). Assume that:

$\left(H_{1}\right)$ the function $p \in C^{1}\left(\left[T_{0}, \infty\right),(0, \infty)\right)$;

$\left(H_{2}\right) p((2 n+1) \tau)-p(2 n \tau)=0, n \in \mathbb{N}$ 
$\left(H_{3}\right)$ there exists $T_{n} \in(2 n \tau,(2 n+1) \tau)$ such that $p^{\prime}(t)>0$ for $t \in\left(T_{n}-\tau, T_{n}\right)$ and $p^{\prime}(t)<0$ for $t \in\left(T_{n},(2 n+1) \tau\right], n \in \mathbb{N}$;

$\left(H_{4}\right) \inf \left\{-\int_{T_{n}}^{(2 n+1) \tau}\left(t-T_{n}\right) p^{\prime}(t) d t, n \in \mathbb{N}\right\}>0$.

Then

$$
\inf \{R((2 n+1) \tau), n \in \mathbb{N}\}>0
$$

Proof We easily see that

$$
\begin{aligned}
R( & (2 n+1) \tau) \\
= & -\int_{2 n \tau}^{(2 n+1) \tau} p^{\prime}(t) \int_{t_{0}}^{t} \frac{x(s-r(s))}{x(s)} d s d t \\
= & -\int_{2 n \tau}^{T_{n}} p^{\prime}(t) \int_{t_{0}}^{t} \frac{x(s-r(s))}{x(s)} d s d t-\int_{T_{n}}^{(2 n+1) \tau} p^{\prime}(t) \int_{t_{0}}^{t} \frac{x(s-r(s))}{x(s)} d s d t \\
\geq & -\int_{2 n \tau}^{T_{n}} p^{\prime}(t) d t \int_{t_{0}}^{T_{n}} \frac{x(s-r(s))}{x(s)} d s-\int_{T_{n}}^{(2 n+1) \tau} p^{\prime}(t) d t \int_{t_{0}}^{T_{n}} \frac{x(s-r(s))}{x(s)} d s \\
& -\int_{T_{n}}^{(2 n+1) \tau} p^{\prime}(t) \int_{T_{n}}^{t} \frac{x(s-r(s))}{x(s)} d s d t \\
= & \left.-\int_{2 n \tau}^{T_{n}} p^{\prime}(t) d t-\int_{T_{n}}^{(2 n+1) \tau} p^{\prime}(t) d t\right) \int_{t_{0}}^{T_{n}} \frac{x(s-r(s))}{x(s)} d s \\
& -\int_{T_{n}}^{(2 n+1) \tau} p^{\prime}(t) \int_{T_{n}}^{t} \frac{x(s-r(s))}{x(s)} d s d t \\
= & {[p(2 n \tau)-p((2 n+1) \tau)] \int_{t_{0}}^{T_{n}} \frac{x(s-r(s))}{x(s)} d s-\int_{T_{n}}^{(2 n+1) \tau} p^{\prime}(t) \int_{T_{n}}^{t} \frac{x(s-r(s))}{x(s)} d s d t } \\
= & -\int_{T_{n}}^{(2 n+1) \tau} p^{\prime}(t) \int_{T_{n}}^{t} \frac{x(s-r(s))}{x(s)} d s d t .
\end{aligned}
$$

Since $x(t)$ is decreasing, $x(t-r(t)) \geq x(t), t \geq t_{0}+\tau$. Thus

$$
\begin{aligned}
R((2 n+1) \tau) & \geq-\int_{T_{n}}^{(2 n+1) \tau} p^{\prime}(t) \int_{T_{n}}^{t} \frac{x(s-r(s))}{x(s)} d s d t \\
& \geq-\int_{T_{n}}^{(2 n+1) \tau}\left(t-T_{n}\right) p^{\prime}(t) d t, \quad n \in \mathbb{N} .
\end{aligned}
$$

In view of $\left(H_{4}\right)$, we get $\inf \{R((2 n+1) \tau), n \in \mathbb{N}\}>0$.

The proof of the lemma is complete.

Theorem 2.1 Suppose that $\left(H_{1}\right)-\left(H_{4}\right)$ hold, $r(t) \geq \tau, p(t)$ is periodic with period $2 \tau$, and

$$
\begin{aligned}
& p^{\prime}(t-\tau)-p^{\prime}(t)>0, \quad t \in\left(T_{n},(2 n+1) \tau\right), n \in \mathbb{N}, \\
& \liminf _{t \rightarrow \infty} \int_{t-r(t)}^{t} p(s) d s>0 .
\end{aligned}
$$

Then all solutions of (1) are oscillatory. 
Proof Assume that (1) has a positive solution $x$. The derivative of the function $R(t)$ is

$$
\begin{aligned}
R^{\prime}(t)= & -p^{\prime}(t) \int_{t_{0}}^{t} \frac{x(s-r(s))}{x(s)} d s+p^{\prime}(t-\tau) \int_{t_{0}}^{t-\tau} \frac{x(s-r(s))}{x(s)} d s \\
= & -p^{\prime}(t) \int_{t-\tau}^{t} \frac{x(s-r(s))}{x(s)} d s-p^{\prime}(t) \int_{t_{0}}^{t-\tau} \frac{x(s-r(s))}{x(s)} d s \\
& +p^{\prime}(t-\tau) \int_{t_{0}}^{t-\tau} \frac{x(s-r(s))}{x(s)} d s \\
= & -p^{\prime}(t) \int_{t-\tau}^{t} \frac{x(s-r(s))}{x(s)} d s \\
& +\left[p^{\prime}(t-\tau)-p^{\prime}(t)\right] \int_{t_{0}}^{t-\tau} \frac{x(s-r(s))}{x(s)} d s, \quad t \geq t_{0}+\tau .
\end{aligned}
$$

Condition (5) implies that $R^{\prime}(t)>0$ for $t \in\left(T_{n},(2 n+1) \tau\right)$. Thus the function $R(t)$ is increasing on $\left(T_{n},(2 n+1) \tau\right), n \in \mathbb{N}$. Since $R\left(T_{n}\right)<0, n \in \mathbb{N}$, by Lemma 2.3 there exist $t_{n} \in\left(T_{n},(2 n+\right.$ 1) $\tau$ ) such that $R\left(t_{n}\right)=0, n \in \mathbb{N}$. Condition $\left(H_{4}\right)$ implies that $\inf \left\{(2 n+1) \tau-T_{n}, n \in \mathbb{N}\right\}>0$. Put

$$
H(t)=p(t)-p(t-\tau), \quad t \in\left(T_{n},(2 n+1) \tau\right], n \in \mathbb{N} .
$$

According to (5) and $\left(H_{2}\right)$, we have

$$
H^{\prime}(t)=p^{\prime}(t)-p^{\prime}(t-\tau)<0, \quad t \in\left(T_{n},(2 n+1) \tau\right),
$$

and $H((2 n+1) \tau)=0, n \in \mathbb{N}$. Then

$$
H(t)=p(t)-p(t-\tau)>0 \quad \text { for } t \in\left(T_{n},(2 n+1) \tau\right), n \in \mathbb{N} .
$$

Now assume that

$$
t_{n} \leq b_{n}=(2 n+1) \tau-\varepsilon, \quad n \in \mathbb{N},
$$

where $0<\varepsilon<\inf \left\{(2 n+1) \tau-T_{n}, n \in \mathbb{N}\right\}$. In view of (4), we get

$$
\begin{aligned}
& \ln \frac{x\left(b_{n}-\tau\right)}{x\left(b_{n}\right)} \\
& =p\left(b_{n}\right) \int_{b_{n}-\tau}^{b_{n}} \frac{x(s-\tau)}{x(s)} d s \\
& \quad+\left[p\left(b_{n}\right)-p\left(b_{n}-\tau\right)\right] \int_{t_{0}}^{b_{n}-\tau} \frac{x(s-\tau)}{x(s)} d s+R\left(b_{n}\right), \quad b_{n} \geq t_{0}+\tau, n \in \mathbb{N} .
\end{aligned}
$$

Condition (6) implies that $x(t-r(t)) / x(t)$ is bounded [7]. Since $x(t-r(t)) / x(t) \geq x(t-\tau) / x(t)$, it is obvious that there exists a constant $K>0$ such that $x(t-\tau) / x(t) \leq K, t \geq T \geq t_{0}+\tau$, where $T$ is sufficiently large. Thus

$$
\ln K \geq p\left(b_{n}\right) \int_{b_{n}-\tau}^{b_{n}} \frac{x(s-r(s))}{x(s)} d s
$$




$$
+\left[p\left(b_{n}\right)-p\left(b_{n}-\tau\right)\right] \int_{t_{0}}^{b_{n}-\tau} \frac{x(s-r(s))}{x(s)} d s+R\left(b_{n}\right), \quad b_{n} \geq T .
$$

Otherwise, for sufficiently large $b_{n} \geq T$, by (7) and the periodicity of $p(t)$, we get

$$
\left[p\left(b_{n}\right)-p\left(b_{n}-\tau\right)\right] \int_{t_{0}}^{b_{n}-\tau} \frac{x(s-r(s))}{x(s)} d s>\ln K
$$

which contradicts (8).

Now assume that there exists a sequence $\left\{t_{n}\right\}$ such that

$$
t_{n} \rightarrow(2 n+1) \tau \quad \text { as } n \rightarrow \infty, \quad R\left(t_{n}\right)=0, \quad t_{n} \in\left(T_{n},(2 n+1) \tau\right), n \in \mathbb{N} .
$$

Then

$$
\begin{aligned}
& R((2 n+1) \tau) \\
& =-\int_{2 n \tau}^{(2 n+1) \tau} p^{\prime}(t) \int_{t_{0}}^{t} \frac{x(s-r(s))}{x(s)} d s d t \\
& =-\int_{2 n \tau}^{T_{n}} p^{\prime}(t) \int_{t_{0}}^{t} \frac{x(s-r(s))}{x(s)} d s d t-\int_{T_{n}}^{(2 n+1) \tau} p^{\prime}(t) \int_{t_{0}}^{t} \frac{x(s-r(s))}{x(s)} d s d t \\
& =-\int_{t_{n}-\tau}^{T_{n}} p^{\prime}(t) \int_{t_{0}}^{t} \frac{x(s-r(s))}{x(s)} d s d t+\int_{t_{n}-\tau}^{2 n \tau} p^{\prime}(t) \int_{t_{0}}^{t} \frac{x(s-r(s))}{x(s)} d s d t \\
& -\int_{T_{n}}^{t_{n}} p^{\prime}(t) \int_{t_{0}}^{t} \frac{x(s-r(s))}{x(s)} d s d t-\int_{t_{n}}^{(2 n+1) \tau} p^{\prime}(t) \int_{t_{0}}^{t} \frac{x(s-r(s))}{x(s)} d s d t \\
& =-\int_{t_{n}-\tau}^{t_{n}} p^{\prime}(t) \int_{t_{0}}^{t} \frac{x(s-r(s))}{x(s)} d s d t+\int_{t_{n}-\tau}^{2 n \tau} p^{\prime}(t) \int_{t_{0}}^{t} \frac{x(s-r(s))}{x(s)} d s d t \\
& -\int_{t_{n}}^{(2 n+1) \tau} p^{\prime}(t) \int_{t_{0}}^{t} \frac{x(s-r(s))}{x(s)} d s d t \\
& =R\left(t_{n}\right)+\int_{t_{n}-\tau}^{2 n \tau} p^{\prime}(t) \int_{t_{0}}^{t} \frac{x(s-r(s))}{x(s)} d s d t-\int_{t_{n}}^{(2 n+1) \tau} p^{\prime}(t) \int_{t_{0}}^{t} \frac{x(s-r(s))}{x(s)} d s d t \\
& =\int_{t_{n}-\tau}^{2 n \tau} p^{\prime}(t) \int_{t_{0}}^{t} \frac{x(s-r(s))}{x(s)} d s d t \\
& -\int_{t_{n}}^{(2 n+1) \tau} p^{\prime}(t) \int_{t_{0}}^{t} \frac{x(s-r(s))}{x(s)} d s d t, \quad n \in \mathbb{N} .
\end{aligned}
$$

Since $t_{n} \rightarrow(2 n+1) \tau \quad$ as $n \rightarrow \infty$, clearly,

$$
\int_{t_{n}-\tau}^{2 n \tau} p^{\prime}(t) \int_{t_{0}}^{t} \frac{x(s-r(s))}{x(s)} d s d t \rightarrow 0
$$

and

$$
-\int_{t_{n}}^{(2 n+1) \tau} p^{\prime}(t) \int_{t_{0}}^{t} \frac{x(s-r(s))}{x(s)} d s d t \rightarrow 0
$$


Thus

$$
R((2 n+1) \tau) \rightarrow 0 \quad \text { as } t_{n} \rightarrow(2 n+1) \tau \text { and } n \rightarrow \infty .
$$

This contradicts $\inf \{R((2 n+1) \tau), n \in \mathbb{N}\}>0$.

The proof of the theorem is complete.

Example Consider the delay differential equation

$$
x^{\prime}(t)+\left(\frac{a}{\pi e}+\delta \sin a t\right) x\left(t-\frac{\pi}{a}\right)=0, \quad t \geq 0,
$$

where $a>0, \delta \in\left(0, \frac{a}{\pi e}\right)$.

Equation (9) is a particular case of (1) when $r(t)=\tau=\frac{\pi}{a}, T_{0}=0$, and

$$
p(t)=\frac{a}{\pi e}+\delta \sin a t .
$$

It is easy to see that $\left(H_{1}\right)$ is satisfied. For condition $\left(H_{2}\right)$, we have

$$
\begin{aligned}
& p((2 n+1) \tau)-p(2 n \tau) \\
& \quad=\frac{a}{\pi e}+\delta \sin a(2 n+1) \frac{\pi}{a}-\frac{a}{\pi e}-\delta \sin a 2 n \frac{\pi}{a} \\
& \quad=\delta[\sin (2 n+1) \pi-\sin 2 n \pi]=0, \quad n \in \mathbb{N} .
\end{aligned}
$$

In condition $\left(H_{3}\right), T_{n}=(2 n+0.5) \frac{\pi}{a}$, and

$$
\begin{aligned}
& p^{\prime}(t)=a \delta \cos a t>0 \quad \text { for } t \in\left((2 n-0.5) \frac{\pi}{a},(2 n+0.5) \frac{\pi}{a}\right), \\
& p^{\prime}(t)<0 \quad \text { for } t \in\left((2 n+0.5) \frac{\pi}{a},(2 n+1) \frac{\pi}{a}\right], n \in \mathbb{N} .
\end{aligned}
$$

For condition $\left(H_{4}\right)$, we get

$$
\begin{aligned}
-a \delta & \int_{(2 n+0.5) \frac{\pi}{a}}^{(2 n+1) \frac{\pi}{a}}\left(t-(2 n+0.5) \frac{\pi}{a}\right) \cos a t d t \\
= & a \delta(2 n+0.5) \frac{\pi}{a} \int_{(2 n+0.5) \frac{\pi}{a}}^{(2 n+1) \frac{\pi}{a}} \cos a t d t-a \delta \int_{(2 n+0.5) \frac{\pi}{a}}^{(2 n+1) \frac{\pi}{a}} t \cos a t d t \\
= & \delta(2 n+0.5) \frac{\pi}{a}[\sin (2 n+1) \pi-\sin (2 n+0.5) \pi]-a \delta\left[\frac{1}{a^{2}} \cos (2 n+1) \pi\right. \\
& \left.+\frac{1}{a}(2 n+1) \frac{\pi}{a} \sin (2 n+1) \pi-\frac{1}{a^{2}} \cos (2 n+0.5) \pi-\frac{1}{a}(2 n+0.5) \frac{\pi}{a} \sin (2 n+0.5) \pi\right] \\
= & -\delta(2 n+0.5) \frac{\pi}{a}-a \delta\left[-\frac{1}{a^{2}}-\frac{1}{a}(2 n+0.5) \frac{\pi}{a}\right] \\
= & -\delta(2 n+0.5) \frac{\pi}{a}-\delta\left[-\frac{1}{a}-(2 n+0.5) \frac{\pi}{a}\right]=\frac{\delta}{a} .
\end{aligned}
$$


Thus

$$
\begin{aligned}
& \inf \left\{-\int_{T_{n}}^{(2 n+1) \tau}\left(t-T_{n}\right) p^{\prime}(t) d t, n \in \mathbb{N}\right\} \\
& \quad=\inf \left\{-a \delta \int_{(2 n+0.5) \frac{\pi}{a}}^{(2 n+1) \frac{\pi}{a}}\left(t-(2 n+0.5) \frac{\pi}{a}\right) \cos a t d t, n \in \mathbb{N}\right\}=\frac{\delta}{a}>0 .
\end{aligned}
$$

In addition, we have

$$
\begin{aligned}
p^{\prime}(t-\tau)-p^{\prime}(t) & =p^{\prime}\left(t-\frac{\pi}{a}\right)-p^{\prime}(t)=a \delta \cos a\left(t-\frac{\pi}{a}\right)-a \delta \cos a t \\
& =a \delta[\cos (a t-\pi)-\cos a t]=a \delta(-\cos a t-\cos a t) \\
& =-2 a \delta \cos a t>0 \quad \text { for } t \in\left((2 n+0.5) \frac{\pi}{a},(2 n+1) \frac{\pi}{a}\right), \quad n \in \mathbb{N},
\end{aligned}
$$

that is, condition (5) is satisfied. Also,

$$
\begin{aligned}
& \int_{t-\frac{\pi}{a}}^{t}\left(\frac{a}{\pi e}+\delta \sin a s\right) d s \\
& =\frac{a}{\pi e} t-\frac{\delta}{a} \cos a t-\frac{a}{\pi e}\left(t-\frac{\pi}{a}\right)+\frac{\delta}{a} \cos a\left(t-\frac{\pi}{a}\right) \\
& =-\frac{\delta}{a} \cos a t+\frac{1}{e}+\frac{\delta}{a} \cos (a t-\pi)=\frac{1}{e}-\frac{\delta}{a} \cos a t-\frac{\delta}{a} \cos a t \\
& =\frac{1}{e}-\frac{2 \delta}{a} \cos a t .
\end{aligned}
$$

Therefore

$$
\begin{aligned}
\liminf _{t \rightarrow \infty} \int_{t-\frac{\pi}{a}}^{t} p(s) d s & =\liminf _{t \rightarrow \infty} \int_{t-\frac{\pi}{a}}^{t}\left(\frac{a}{\pi e}+\delta \sin a s\right) d s \\
& =\frac{1}{e}-\frac{2 \delta}{a}>0, \quad \delta \in\left(0, \frac{a}{\pi e}\right),
\end{aligned}
$$

so that all conditions of Theorem 2.1 are satisfied, which means that all solutions of (9) are oscillatory.

Observe, however, that

$$
\limsup _{t \rightarrow \infty} \int_{t-\frac{\pi}{a}}^{t} p(s) d s=\frac{1}{e}+\frac{2 \delta}{a}<\frac{\pi+2}{\pi e}<1, \quad \delta \in\left(0, \frac{a}{\pi e}\right)
$$

and

$$
\liminf _{t \rightarrow \infty} \int_{t-\frac{\pi}{a}}^{t} p(s) d s=\frac{1}{e}-\frac{2 \delta}{a}<\frac{1}{e}, \quad \delta \in\left(0, \frac{a}{\pi e}\right),
$$

which means that conditions (2) and (3) are not satisfied.

Moreover, the function $f(t)$ is not slowly varying at infinity. Indeed,

$$
f(t)=\int_{t-\frac{\pi}{a}}^{t} p(s) d s=\frac{1}{e}-\frac{2 \delta}{a} \cos a t, \quad \delta \in\left(0, \frac{a}{\pi e}\right),
$$


and

$$
\begin{aligned}
f(t+s)-f(t) & =-\frac{2 \delta}{a} \cos a(t+s)+\frac{2 \delta}{a} \cos a t \\
& =\frac{2 \delta}{a}[\cos a t-\cos a(t+s)], \quad s \in \mathbb{R}
\end{aligned}
$$

For $s=\pi / a$, we get

$$
\begin{aligned}
f\left(t+\frac{\pi}{a}\right)-f(t) & =\frac{2 \delta}{a}\left[\cos a t-\cos a\left(t+\frac{\pi}{a}\right)\right] \\
& =\frac{2 \delta}{a}[\cos a t+\cos a t]=\frac{4 \delta}{a} \cos a t \not \rightarrow 0 \text { as } t \rightarrow \infty, \delta \in\left(0, \frac{a}{\pi e}\right) .
\end{aligned}
$$

Thus Theorem 1.1 cannot be applied. Recall (see, e.g., $[3,12])$ that a function $f:\left[t_{0}, \infty\right) \rightarrow$ $\mathbb{R}$ is slowly varying at infinity if for every $s \in \mathbb{R}$,

$$
f(t+s)-f(t) \rightarrow 0 \quad \text { as } t \rightarrow \infty
$$

\section{Acknowledgements}

The authors would like to express their gratitude to the anonymous referees for their help to improve the manuscript.

\section{Funding}

The first author was supported by the Special Account for Research of ASPETE through the funding program Strengthening research of ASPETE faculty members.

\section{Availability of data and materials}

Data sharing is not applicable to this paper as no datasets were generated or analyzed during the current study.

\section{Competing interests}

The authors declare that they have no competing interests.

\section{Authors' contributions}

The authors declare that they have read and approved the final manuscript.

\section{Author details}

${ }^{1}$ Department of Electrical and Electronic Engineering Educators, School of Pedagogical and Technological Education (ASPETE), Athens, Greece. ${ }^{2}$ Department of Applied Mathematics, Faculty of Mechanical Engineering, University of Žilina, Žilina, Slovak Republic.

\section{Publisher's Note}

Springer Nature remains neutral with regard to jurisdictional claims in published maps and institutional affiliations.

Received: 7 December 2020 Accepted: 18 January 2021 Published online: 28 January 2021

\section{References}

1. Džurina, J., Grace, S.R., Jadlovská, I., Li, T.: Oscillation criteria for second-order Emden-Fowler delay differential equations with a sublinear neutral term. Math. Nachr. 293(5), 910-922 (2020)

2. Erbe, L.H., Kong, Q., Zhang, B.G.: Oscillation Theory for Functional Differential Equations. Dekker, New York (1995)

3. Garab, A., Pituk, M., Stavroulakis, I.P.: A sharp oscillation criterion for a linear delay differential equation. Appl. Math. Lett. 93, 58-65 (2019)

4. Györi, I., Ladas, G.: Oscillation Theory of Delay Differential Equations with Applications. Oxford University Press, New York (1991)

5. Chatzarakis, G.E., Li, T.: Oscillation criteria for delay and advanced differential equations with nonmonotone arguments. Complexity 2018, 8237634 (2018)

6. Chatzarakis, G.E., Grace, S.R., Jadlovská, I., Li, T., Tunç, E.: Oscillation criteria for third-order Emden-Fowler differential equations with unbounded neutral coefficients. Complexity 2019, 5691758 (2019)

7. Koplatadze, R.G., Chanturija, T.A.: On the oscillatory and monotonic solutions of first order differential equations with deviating arguments. Differ. Uravn. 18, 1463-1465 (1982)

8. Ladas, G.: Sharp conditions for oscillations caused by delays. Appl. Anal. 9(2), 93-98 (1979)

9. Ladas, G., Lakshmikantham, V., Papadakis, L.S.: Oscillations of higher-order retarded differential equations generated by the retarded arguments. In: Schmitt, K. (ed.) Delay and Functional Differential Equations and Their Applications, pp. 219-231. Academic Press, New York (1972) 
10. Li, T., Rogovchenko, Y.V.: On the asymptotic behavior of solutions to a class of third-order nonlinear neutral differential equations. Appl. Math. Lett. 105(106293), 1-7 (2020)

11. Li, T., Rogovchenko, Y.V.: Oscillation criteria for even-order neutral differential equations. Appl. Math. Lett. 61, 35-41 (2019)

12. Ash, J.M., Erdös, P., Rubel, L.A.: Very slowly varying functions. Aequ. Math. 10, 1-9 (1974)

Submit your manuscript to a SpringerOpen ${ }^{\mathcal{O}}$ journal and benefit from:

- Convenient online submission

Rigorous peer review

- Open access: articles freely available online

- High visibility within the field

- Retaining the copyright to your article

Submit your next manuscript at $\boldsymbol{\nabla}$ springeropen.com 